\title{
Allele-level HLA matching reduces early rejection in lung transplant recipients
}

\author{
Raja Rajalingam \\ Immunogenetics and Transplantation Laboratory, Department of Surgery, University of California San Francisco, San Francisco, CA, USA \\ Correspondence to: Raja Rajalingam, PhD. Professor of Clinical Surgery, Department of Surgery, Director, Immunogenetics and Transplantation \\ Laboratory, University of California San Francisco, 3333 California Street, Suite 150, San Francisco, CA 94118, USA. \\ Email: Rajalingam.Raja@ucsf.edu. \\ Provenance and Peer Review: This is an invited article commissioned and reviewed by the Section Editor Jianfei Shen, MD (Taizhou Hospital of \\ Zhejiang Province, Wenzhou Medical University, Taizhou, China). \\ Comment on: Zhang J, Liu D, Zhang C, et al. The value of high-resolution HLA in the perioperative period of non-sensitized lung transplant \\ recipients. Ann Transl Med 2020;8:37.
}

Submitted Jan 28, 2020. Accepted for publication Feb 27, 2020.

doi: $10.21037 / \mathrm{atm} .2020 .02 .64$

View this article at: http://dx.doi.org/10.21037/atm.2020.02.64

Nearly $40 \%$ of the genes in the human major histocompatibility complex (MHC), including human leukocyte antigen (HLA) loci associate to immune function $(1,2)$. HLA genes evolved to be highly polymorphic to combat infection $(1,2)$. In therapeutic transplant setting, "HLA mismatch" happens when the donor HLA on the allograft differs from the recipient. HLA mismatch leads to the activation of alloreactive $\mathrm{T}$ cells, which can cause acute cellular rejection (ACR) within six months of lung transplantation (3). ACR is the major risk factor for chronic lung allograft dysfunction (CLAD) (4). Mismatched donor HLA antigens are also targets for the development of de nova donor-specific HLA antibodies ( $d n \mathrm{DSA})$ which play augmented roles in both acute and chronic lung transplant rejection (5-8).

HLA matching is given an important priority in the national allocation of deceased-donor kidneys because of the superior survival of matched kidneys (9). Data concerning the impact of HLA matching on lung transplant outcomes is limited (10-17). Three large-scale registry studies demonstrated that survival following lung transplantation decreased as the number of HLA mismatches increased (18-20). HLA mismatch quantification is limited by $0-2$ antigen values per locus, e.g., 0 -antigen mismatch, 1 -antigen mismatch, or 2-antigens mismatch. The number of HLA mismatches are not strictly proportional to $d n$ DSA development because HLA antibodies are generated against 'epitopes', short polymorphic amino acid sequence motifs shared among multiple HLA alleles within the same and/ or different loci. The shared polymorphism explains why a single HLA antigen mismatch can provoke antibodies directed against an array of HLA antigens.

For these biological reasons, it is fitting to define HLA molecular mismatch at the amino acid sequence level to quantify mismatch, which can be translated into the recipient's ability to respond against the donor's mismatched HLA antigens. Molecular matching will likely improve the precision of immunological risk assessment with $d n$ DSA development as the readout for alloimmune response. Molecular matching can be scored by the physicochemical properties such as, the amino acid sequence mismatch score, the electrostatic property mismatch score, and the hydrophobic property mismatch score $(21,22)$. The HLA matchmaker identifies "eplets", small patches of surface-exposed amino acids on mismatched HLA (either linear or discontinuous) with the ability to induce an antibody response $(23,24)$. The quantity of mismatched eplets, or physicochemical disparities between donor and recipient alleles has been shown to correlate with $d n$ DSA development, rejection, chronic glomerulopathy, and kidney graft loss (25-27). Most of these studies in kidney transplant analyzed only three (HLA-A, B, and DRB1) of the 11 known HLA loci as the expense of sequencing all loci would be cost-prohibitive. There has been no comprehensive study 
investigating the role of HLA eplet or physicochemical matching on lung allograft survival.

In the issue of Annals of Translational Medicine, Zhang et al. describes the effects of HLA-A,B,C, DR and DQ allele-level mismatches on primary graft dysfunction (PGD) and acute rejection (AR) on 59 lung transplantations performed from April 1, 2018, to June 30, 2019 (28). The study found more mismatches at the allele-level compared to the antigen-level $(8.31 \pm 1.75$ vs. $7.19 \pm 1.61 ; \mathrm{P}=0.0005)$ and the severity of PGD increases as the number of HLAABCDRDQ mismatch increases at the antigen-level as well as at the allele-level. The study also found that more HLA-DQ mismatch is significantly associated with severe PGD. One of the interesting findings from this study is the relevance of HLA mismatching in the early lung allograft rejection within a perioperative period (1 month) in unsensitized recipients ( $86.44 \%$ are male). However, these findings raise many questions. The paper mistakes HLA high-resolution typing mismatch with eplet mismatch. The method indicates that the eplet matching has been assessed by HLA Matchmaker program (http://www.hlamatchmaker. net), but no data on eplet mismatch is presented in the paper. The paper presents high resolution matching, and mistakenly calls it as eplet matching. The method used for high-resolution HLA typing is also a problem. The paper states that HLA allelic genotyping (-A, -B, -C, -DRB1, and -DQB1/A1) was performed by sequencebased typing (SBT) based on the Luminex technology (One Lambda, Inc., Canoga Park, CA, USA). The fact is that the Luminex-based typing used in this study is a probe-based hybridization method that detects known polymorphism and gives intermediate-level typing only. High resolution typing requires the direct sequencing of HLA genes using Sanger method or next generation sequencing methods.

In addition to HLA mismatches, the study also found a positive correlation between the severity of PGD and mechanical ventilation time or ICU time. It is unclear if the recipients with grade 3 PGD had high level of HLA-DQ mismatch, or longer mechanical ventilation time, or longer ICU stay. A multivariate analysis with a bigger cohort will address this important question. Notwithstanding these limitations, this study shows that precise degree of HLA allele matching plays a key role in the occurrence of perioperative PGD and acute rejection.

\section{Acknowledgments}

Funding: None.

\section{Footnote}

Conflicts of Interest: The author has no conflicts of interest to declare.

Ethical Statement: The author is accountable for all aspects of the work in ensuring that questions related to the accuracy or integrity of any part of the work are appropriately investigated and resolved.

Open Access Statement: This is an Open Access article distributed in accordance with the Creative Commons Attribution-NonCommercial-NoDerivs 4.0 International License (CC BY-NC-ND 4.0), which permits the noncommercial replication and distribution of the article with the strict proviso that no changes or edits are made and the original work is properly cited (including links to both the formal publication through the relevant DOI and the license). See: https://creativecommons.org/licenses/by-nc-nd/4.0/.

\section{References}

1. Complete sequence and gene map of a human major histocompatibility complex. The MHC sequencing consortium. Nature 1999;401:921-3.

2. Robinson J, Halliwell JA, Hayhurst JD, et al. The IPD and IMGT/HLA database: allele variant databases. Nucleic Acids Res 2015;43:D423-31.

3. Hopkins PM, Aboyoun CL, Chhajed PN, et al. Prospective analysis of 1,235 transbronchial lung biopsies in lung transplant recipients. J Heart Lung Transplant 2002;21:1062-7.

4. Khalifah AP, Hachem RR, Chakinala MM, et al. Minimal acute rejection after lung transplantation: a risk for bronchiolitis obliterans syndrome. Am J Transplant 2005;5:2022-30.

5. Glanville AR. Antibody-mediated rejection in lung transplantation: myth or reality? J Heart Lung Transplant 2010;29:395-400.

6. Levine DJ, Glanville AR, Aboyoun C, et al. Antibodymediated rejection of the lung: A consensus report of the International Society for Heart and Lung Transplantation. J Heart Lung Transplant 2016;35:397-406.

7. Le Pavec J, Suberbielle C, Lamrani L, et al. De-novo donor-specific anti-HLA antibodies 30 days after lung transplantation are associated with a worse outcome. J Heart Lung Transplant 2016;35:1067-77.

8. Tikkanen JM, Singer LG, Kim SJ, et al. De Novo DQ 
Donor-Specific Antibodies Are Associated with Chronic Lung Allograft Dysfunction after Lung Transplantation. Am J Respir Crit Care Med 2016;194:596-606.

9. Bresnahan BA, Johnson CP, McIntosh MJ, et al. A comparison between recipients receiving matched kidney and those receiving mismatched kidney from the same cadaver donor. Am J Transplant 2002;2:366-72.

10. Smith MA, Sundaresan S, Mohanakumar T, et al. Effect of development of antibodies to HLA and cytomegalovirus mismatch on lung transplantation survival and development of bronchiolitis obliterans syndrome. J Thorac Cardiovasc Surg 1998;116:812-20.

11. Brugiere O, Thabut G, Suberbielle C, et al. Relative impact of human leukocyte antigen mismatching and graft ischemic time after lung transplantation. J Heart Lung Transplant 2008;27:628-34.

12. Wisser $W$, Wekerle $T$, Zlabinger $G$, et al. Influence of human leukocyte antigen matching on long-term outcome after lung transplantation. J Heart Lung Transplant 1996;15:1209-16.

13. Sundaresan S, Mohanakumar T, Smith MA, et al. HLA-A locus mismatches and development of antibodies to HLA after lung transplantation correlate with the development of bronchiolitis obliterans syndrome. Transplantation 1998;65:648-53.

14. Schulman LL, Weinberg AD, McGregor C, et al. Mismatches at the HLA-DR and HLA-B loci are risk factors for acute rejection after lung transplantation. Am J Respir Crit Care Med 1998;157:1833-7.

15. Love RB, Meyer KC, Devito-Haynes LD, et al. Effect of HLA-DR mismatch on lung transplant outcome. J Heart Lung Transplant 2001;20:177.

16. Chalermskulrat W, Neuringer IP, Schmitz JL, et al. Human leukocyte antigen mismatches predispose to the severity of bronchiolitis obliterans syndrome after lung transplantation. Chest 2003;123:1825-31.

17. Quantz MA, Bennett LE, Meyer DM, et al. Does human leukocyte antigen matching influence the outcome of lung transplantation? An analysis of 3,549 lung transplantations. J Heart Lung Transplant 2000;19:473-9.

18. Opelz G, Susal C, Ruhenstroth A, et al. Impact of HLA compatibility on lung transplant survival and evidence for an HLA restriction phenomenon: a collaborative

Cite this article as: Rajalingam R. Allele-level HLA matching reduces early rejection in lung transplant recipients. Ann Transl Med 2020;8(6):275. doi: 10.21037/atm.2020.02.64 transplant study report. Transplantation 2010;90:912-7.

19. Hayes D, Jr., Black SM, Tobias JD, et al. Influence of human leukocyte antigen mismatching on bronchiolitis obliterans syndrome in lung transplantation. J Heart Lung Transplant 2016;35:186-94.

20. Peltz M, Edwards LB, Jessen ME, et al. HLA mismatches influence lung transplant recipient survival, bronchiolitis obliterans and rejection: implications for donor lung allocation. J Heart Lung Transplant 2011;30:426-34.

21. Kosmoliaptsis V, Sharples LD, Chaudhry A, et al. HLA class I amino acid sequence-based matching after interlocus subtraction and long-term outcome after deceased donor kidney transplantation. Hum Immunol 2010;71:851-6.

22. Kosmoliaptsis V, Sharples LD, Chaudhry AN, et al. Predicting HLA class II alloantigen immunogenicity from the number and physiochemical properties of amino acid polymorphisms. Transplantation 2011;91:183-90.

23. Duquesnoy RJ, Marrari M, Mulder A, et al. Structural aspects of human leukocyte antigen class I epitopes detected by human monoclonal antibodies. Hum Immunol 2012;73:267-77.

24. Duquesnoy RJ, Askar M. HLAMatchmaker: a molecularly based algorithm for histocompatibility determination. V. Eplet matching for HLA-DR, HLA-DQ, and HLA-DP. Hum Immunol 2007;68:12-25.

25. Kosmoliaptsis V, Mallon DH, Chen Y, et al. Alloantibody Responses After Renal Transplant Failure Can Be Better Predicted by Donor-Recipient HLA Amino Acid Sequence and Physicochemical Disparities Than Conventional HLA Matching. Am J Transplant 2016;16:2139-47.

26. Wiebe C, Kosmoliaptsis V, Pochinco D, et al. A Comparison of HLA Molecular Mismatch Methods to Determine HLA Immunogenicity. Transplantation 2018;102:1338-43.

27. Delion A, Girerd S, Duarte K, et al. Which is the best predictor of de novo donor-specific antibodies in a cohort of non-sensitized first kidney transplantation: Antigenic, allelic, epitope, or physiochemical HLA mismatches? Clin Transplant 2019;33:e13508.

28. Zhang J, Liu D, Zhang C, et al. The value of highresolution HLA in the perioperative period of nonsensitized lung transplant recipients. Ann Transl Med $2020 ; 8: 37$. 